\title{
The Functions of SBST and DBST in South African Primary Schools
}

Sefudi Isaac Nong

Inclusive Education
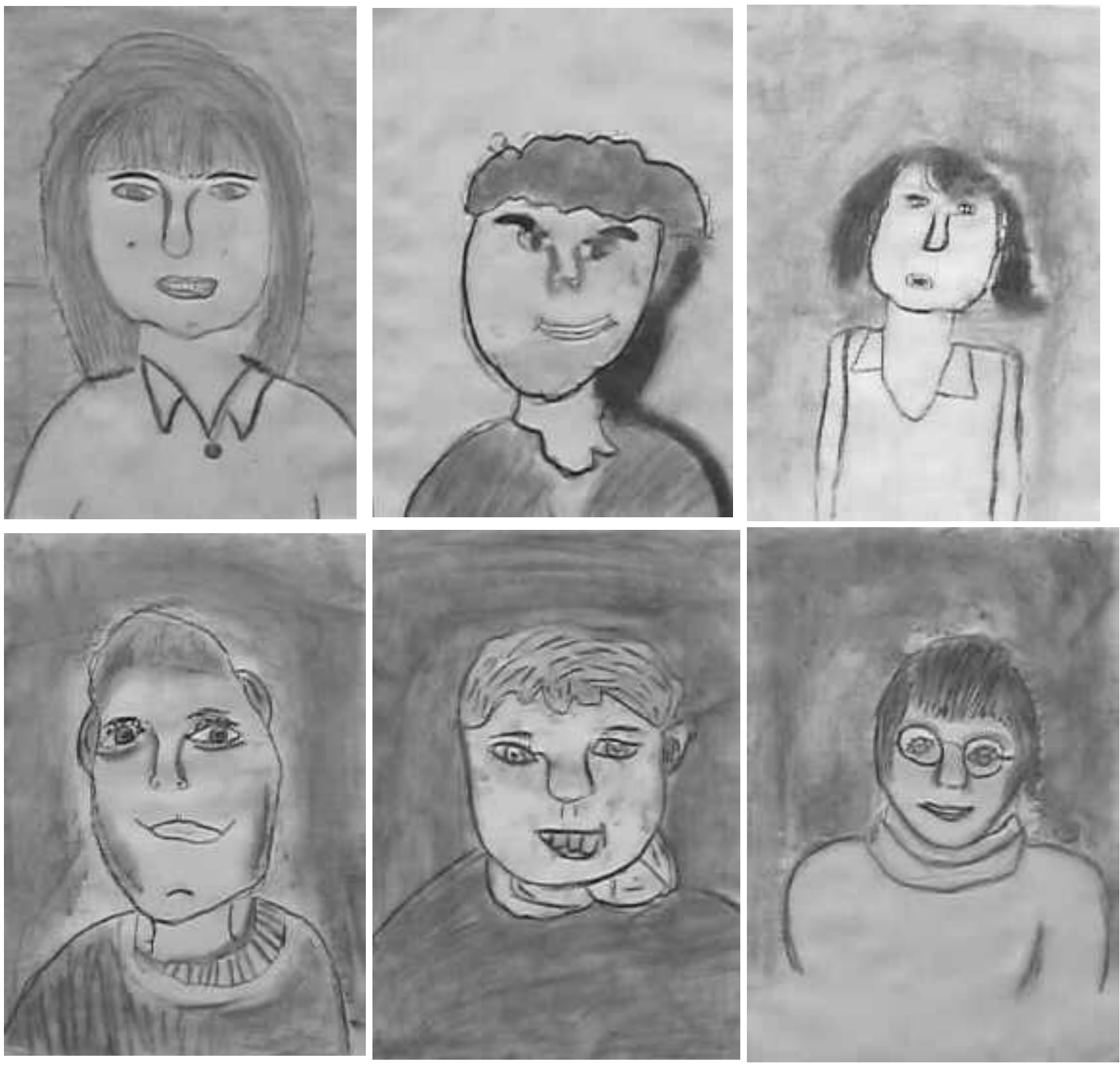
Table of contents

Abstract...................................................................... 1245

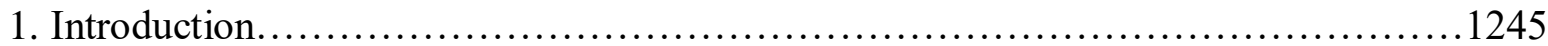

2. Literature Review.......................................................... 1245

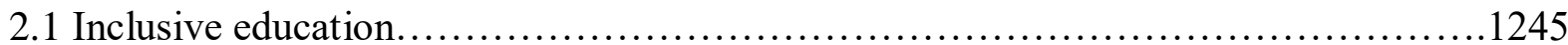

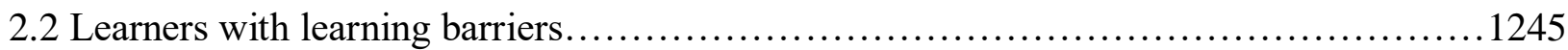

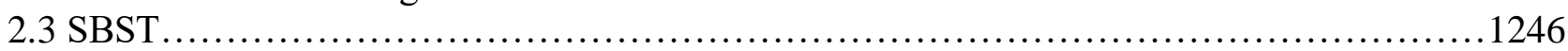

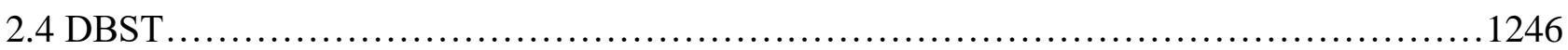

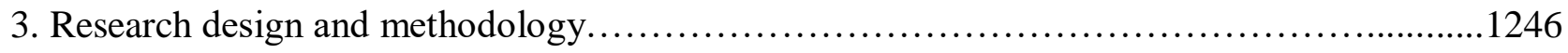

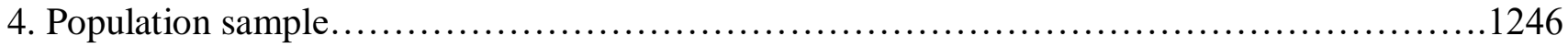

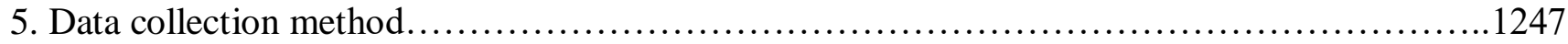

6. Data analysis, finding and discussion..................................................... 1247

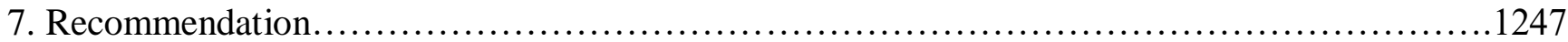

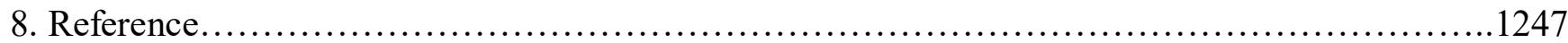


Abstract:- This research focuses on the functions of the SBST and DBST in supporting the teachers to address the challenges they face in teaching inclusive education in South African primary schools. In some instances, inclusive education seeks to identify and dismantle barriers to education faced by all the learners, so that they can have access to quality education. Furthermore participate effectively in class and achieve optimal academic outcomes at school. Although inclusive education has developed and established itself as field of educational research, policy and practice in a relatively short period of time as stated some of the literatures. There is inadequate knowledge and lack of skills in supporting teachers involved in teaching inclusive education and there has been no proper training for those teachers. The collected data has revealed some of the frustrations and challenges experienced by teachers who need support in teaching learners inclusive education. Teachers in South African public primary schools have been assigned to teach classes that include learners with special needs, in a regular classes as emphasised by Whitepaper 6. Over and above, this move requires positive experiences and the support of inclusive schooling, otherwise teachers are unlikely to succeed in teaching inclusive classes (Ernst and Rogers, 2009Guskey, 2002). In responding to what is perceived unjust for these learners experiencing barriers to learning and the teachers involved in teaching inclusive education, this paper attempts to chart the relationship and functions of SBST and DBST as a means for analysing the weakening support offered to inclusive education.

Keywords:- Inclusive education, Learners with learning barriers, SBST and DBST

\section{INTRODUCTION}

Many children are unable to read and write correctly in South African government primary schools. This matter being argued that, was exacerbated by poverty and poor socio economic imbalances as a result of the oppressive colonial government that ruled South Africa before 1994. Yet, South Africa has gained democracy in 1994, but the legacy of the past colonial oppression is enduring to pose segregation amongst South African learners.

One of the factors that attest to this assumption was the articulation by the Minister of basic Education when she said that, Schools that are not ready, won't reopen ( eNCA:2020), of which those that were considered to be ready were private schools, multi-racial schools and lastly government schools. The minister was very precise and doing all in her power to protect the lives of the South African learners from covid19 in her statement, but the situation of the learners experiencing barriers to learning it becomes worse. According to Mahlo (2011:8), "education support services are under-resourced and unable to deal with the large number of learners in need - their barriers to learning are not being addressed" .Notwithstanding that, there should be SBSTs and District-Based Support Teams
(DBSTs) that should be responsible for empowering teachers on how to address barriers to learning (White Paper 6). As arguably by OECD \& UNESCO (2017) that, "education needs to be based upon principles of equity and inclusion to lay the foundations for effective citizenship in civil society". Inclusive education was established in Salamanca, Spain, from 7 to 10June 1994, towards the objective of Education for All. It was also enshrined in UNESCO(1994:6) that, "It will also oblige schools to accommodate all children regardless of their physical, intellectual, social, emotional, linguistic or other conditions".

\section{LITERATURE REVIEW}

According to Section 27(2016:14), "the DBST, like other examples of district and provincial officialdom, appears to lack the capacity and expertise necessary to guide SBSTs in the implementation of an inclusive education policy". It was further alluded in Section 27(2016:14) that, "some even have a negative attitude towards the potential of children with disabilities to learn, and the importance of education that accommodates all barriers to learning".

Considering Reid (2010) when said that, "a fully inclusive educational setting necessitates planning, trained teachers and other support staff'. It can be argued that quality and definition of service delivery is vital to the training and skills of teachers. In addition, clear guidelines for the roles and functions of these teams need to be developed as a matter of urgency (DBE Inclusion Focus Week, 2017:174). Due to the fact that some scholars are of the assumption that, inclusive education policies and practices may intensify experiences of exclusion and underachievement (Dyson \& Slee, 2001; Cologon, 2013; Walton, 2016; Greenstein, 2016; Tomlinson, 2017).

\section{A. Inclusive Education \\ In many researches inclusive education has been used} to advocate increase to access, presence, participation and success for all learners in education. In a broader essence, inclusive education ought to provide a principled and systematic approach to identifying and dismantling barriers for vulnerable populations. Deppeler and Sharma (2013:6) are of argue that, "Inclusive education is a contentious term that lacks a tight conceptual focus, which may contribute to some misconception and confused practice". Hence, there are uncertainty and confusion that has also grown around the theory and practice of inclusive education and left many teachers considering it as being forced upon them.

\section{B. Learners with learning barriers}

The researcher suggest that, the term barriers to learning may refer to the difficulties and challenges that hinders learners to participate effectively in the classroom and reach their full potential. They can originate prenatally, developed during the children milestone or being resulted by the school or by the education system itself. It is believed that the number of learners with learning barriers increases significantly. According to Landberg .et.al 
(2005:363), "In almost all classes, there are learners experiencing learning barriers". In many studies conducted, a collaborative approach was explored as a way of strengthening the support for teachers in dealing with the challenges of addressing barriers to learning in the class but the support was said to be fragmented due to inadequate training and poor monitoring by SBST.

\section{SBST (School based support team)}

The researcher consider to be ideal that, the support teams at all levels of education to play a primary role in identifying and addressing barriers to learning in their immediate context (Donald et al., 2009). These teams interact with district-based support teams who provide integrated and, if necessary, more specialized services (DoE, 2005a). It is against this background that the composition and functions of one of these team would be as indicated as follows, but not limited to this composition as the focus is only drawn to the context of this study.

\section{The principal of the school}

The coordinator of SBST, Head of Department (HoD) for Life Orientation or chosen by staff, senior educator(Teachers who have more than ten years' experience)

$>$ The referring educator - any teacher who is referring the learner to the SBST

$>$ The scriber (who will take minutes during meetings)

$>$ The elected educator per phase, for example, deputy principal

$>$ The elected educator per grade

$>$ The elected educator from the following committees: LTSM(Learning and Teaching Support Material), SAT (School Assessment Team), Sports, Care and Support (HIV and AIDS), and Gender

$>$ School Governing Body (SGB): one member (optional) either from teacher or parental component.

> Therapist Psychologist, Occupational Therapist, Speech Therapist, NGO and other stakeholders, for example, Department of Health, Social Development and other relevant departments

According to the Ofsted report (2006), "the inclusion agenda has been positively supported by schools in such a way that learners' barriers will be removed through support". Hence it is considered pivotal for the SBST to develop intensive strategy in supporting teachers to address learning barriers. Engelbrecht, Engelbrecht, Green and Naicker (2010:158) are concerned that, "people working in collaborative teams can accomplish more than individuals working on their own". Whereas, it is a general feature of schooling, but its particular characteristics vary depending upon local context (Urwick \& Elliott, 2010; ChestertonKhayat, 2015; Nguyen, 2015, 2016 \& 2018).

\section{DBST (District based support team)}

There are anecdotal reports concerning the disproportional referral of minority learner's populations to special education (over-referral and under-referral) as a result of screening learners with tools which are irrelevant. Literally as stated by Farkas and Morgan, (2010) that, "once "you take other learners characteristics - notably family income and achievement - into account, racial minority learners are less likely to be identified for special education than white learners". On contrary it is arguably that socio economic imbalances it is considered a contributory factor in this regard not specifically race (Black nor White learners). This necessitates DBST full engagement with the essence of supporting SBST with the tracking of the emergence and rise of learning barriers and facilitating the reasonable referral of the learners.

\section{RESEARCH DESIGN AND METHODOLOGY}

According to Babbie \& Mouton (2007),’the research design refers to the blueprint or the way in which a study is structured to conduct it successfully". This research chose a mixed approach consisting of quantitative and qualitative research. The research instrument chosen is a survey, but specifically a questionnaire so as to engage with the depth of the research. Questionnaires are lists of surveys questions which are given to respondents designed to elicit specific data. In designing the questionnaire, utmost importance was given to ensure accurate data was collected so that the results are interpretable and generalizable. Then the researcher opted for qualitative data, since it can be extracted from participant narratives based on personal immersed experiences

In terms of methodology, the research chose an interpretive approach. This would allow for finding key themes and labelling them. Three questions were provided on the questionnaire.

How do school-based support teams (SBST) and DBST support teachers teaching inclusive education?

$>$ What type of support does the DBST offer to SBST?

$>$ What resources are available for supporting teachers teaching inclusive education?

The questionnaire was designed to be as simple and effective as possible. Lastly, since the research involved human participants, the researchers aligned themselves with ethical behavior recommended by experts. No names or affiliations were provided in the data.

Regarding data analysis, the research chose a descriptive analytical approach. This was in line with the qualitative questions asked.

\section{POPULATION AND SAMPLE}

8 (eight) teachers were chosen from three different primary schools to participate in this study. Mature teachers of 40 years + plus were chosen for their experience within the field. The researcher sought for an equal gender balance of male/female.

The 8 (eight) teachers were earmarked from a variety of different fields such as the SBST Coordinator, Phase representer, Referral educator, and (HIV and AIDS) Coordinator. From this population, purposive sampling was 
used to select participants for the study. Because the population was predetermined, sampling was not necessary. Thus "non-probability" sampling played a large role in this study.

\section{DATA COLLECTION METHOD}

Data was collected via email. This was suitable given the trying times of the COVID-19 epidemic. Email questionnaires have a higher response rate than normal questionnaires. They are furthermore cost effective than physically carrying out person-to-person interviews.

\section{DATA ANALYSIS, FINDING AND DISCUSSION}

In terms of the first question, Respondent A stated that, the current state of support offered by the SBST and DBST for teachers teaching inclusive education is very poor and there are no official inclusive education classes. Then further stated that, it make it highly difficult for the leaners to be progressive in their grades.

Respondent B declared that the current state of support offered by DBST to SBST is very narrow in terms of addressing learner's barriers, as many learners have intellectual, hearing and other barriers that might not be even easily to diagnose.

Respondent $\mathrm{C}$ was more direct in his response noting that the "current support offered by SBST and DBST to teachers is fragment and devalue the responsibility of the learners for their own learning." He further states that consequently, the teachers take the brunt of responsibility and end up awarding those learners marks just to progress them to other grades.

Respondent D indicated that, they are prone to errors as SBST and they give learners less time to think and answer questions correctly and furthermore not taking into account psycho-social traits of the particular learners in question.

\section{RECOMMENDATIONS}

Consequently, the recommendation was not to limit data collected, but to expand the data sets so as to build comprehensive and distinct pictures of the educational experiences and quality of achievements by leaners with learning difficulties. The researcher suggest that, there is a vast need for an expanded investigation that will look into the educational experiences and attainments of learners with learning barriers in South African primary schools. Furthermore, the SBST roles and functions should be stretched to capture the distinctiveness of the schools as well as the learners in need and provide for indicators of hope for the future inclusive programme reformed. The data also reveals that, there is an increasing calibration of learner's pedagogical cohorts and their disablement in the teaching and learning process as a result of poor support for inclusive education. The researcher suggest that, there is a need for uniform approach in addressing barriers to learning and further studies to be conducted in this topic.

\section{REFERENCES}

[1]. Babbie, E. \& Mouton, J. 2007. The Practice of Social Research. South Africa: Oxford University Press

[2]. Chanel 403.2020.eNCA:News.25 June

[3]. Deloitte Access Economics (2017) Review of education for students with disability in Queensland state schools. Brisbane: Department of Education and Training. http://education.qld.gov.au/schools/disability/docs/dis ability-review-report.pdf

[4]. Department of Education. (2001). White Paper 6: Building an Inclusive Education and Training System.Pretoria: Government Printers

[5]. DEPARTMENT OF EDUCATION (DoE). See South Africa

[6]. Department of Education. 2017. Inclusion Focus Week. Pretoria. Government printers

[7]. DONALD, D., LAZARUS, S. \& LOLWANA, P. 2009. Educational psychology in social context. 3rd Edition. Oxford University Press. Cape Town.

[8]. Dyson, A. \& Slee, R. (2001). Special Needs education from Warnock to Salamanca: the Triumph of Liberalism? In R. Phillips and J. Furlong (Eds.). Education, Reform, and the State. London: Taylor \& Francis

[9]. Ernst, C; \& Rogers, M. R. (2009).Development of the inclusion attitude scale for high school teachers. Journal of Applied School Psychology. Vol.25 (3). pp. 305-322.

[10]. Engelbrecht, L., Engelbrecht, P., Green, L., \& Naicker, S. (2010). Inclusive Education in action in South Africa. Pretoria: Van Schaik.

[11]. Florian, L., Rouse, L. \& Black-Hawkins, K. (2017). Achievement and inclusion in schools. London: Routledge. Ford.

[12]. Hibel, J., Farkas, G., Morgan, P. L. (2010). Who is placed into special education? Sociology of Education, 83, 312-332.

[13]. LANDSBERG, E. 2005. Learning Support. (In Landsberg, E., Kruger, D. \& Nel, N. eds. Addressing barriers to learning: A South African perspectives. Pretoria. Van Schaik.

[14]. Mahlo, F.D. (2011). Experiences of learning Support Teachers in the Foundation Phase. PhD thesis. University of South Africa: Pretoria.

[15]. Nguyen, X. T. (2018). Critical disability studies at the edge of global development: why do we need to engage with southern theory? Canadian Journal of Disability Studies, 7(1), 1-25.

[16]. Nguyen, X. T. (2015). The journey to inclusion. Rotterdam, Sense Publishers.

[17]. Nguyen, X. T. (2016). Girls with Disabilities in the Global South: Rethinking the Politics of Engagement. Girlhood Studies, 9(1), 53.

[18]. OECD (2017) Education at a Glance 2017: OECD Indicators. Paris: OECD Publishing. 
[19]. Ofsted (2006) Inclusion: Does It Matters Where Pupils Are Taught. London: Ofsted

[20]. Reid, C.M. 2010. The Inclusive Classroom: How Inclusive in Inclusion. Online ERIC

[21]. Document ED509705. Accessed 17 December 2011 at: http:www.eric.ed.gov/PDFS/ED509705.pdf.

[22]. SOUTH AFRICA. Department of Education. 1997(a). Quality education for all. Report of the National Commission on Special Needs Education and Training (NCSNET) and National Committee for Education Support Services (NCESS). Pretoria: Department of Education.

[23]. United Nations Educational, Scientific, and Cultural Organization (UNESCO). (1994). The Salamanca statement and framework for action on special needs education. Adopted by the World Conference on Special Needs Education: Access and Quality, Salamanca, Spain, 7-10 June 1994. Paris: UNESCO www.Section 27.org.za accessed 2020/07/28 